\title{
RAP Editorial
}

Alketa Peci

Fundaçao Getulio Vargas / Escola Brasileira de Administração Pública e de Empresas

Rio de Janeiro / RJ - Brasil

Public Administration as an age-old activity, traces of which can be found in any remnants of human civilization that have been organized in such a way as to attain safety, well-being and social harmony, is substantially different from Public Administration as a systematized field of knowledge. Since the end of the $19^{\text {th }}$ Century, this field of knowledge has been responsible for responding intellectually to the challenges imposed by the consolidation of public bureaucracy in different national contexts characterized by an expanding role of the State. The close of the $19^{\text {th }}$ Century also marked a change in the focus of Public Administration, which began to look at separating politics from management, as well as at better understanding the tensions resulting from the overlap of this institution and its authoritarian tendencies (bureaucracy) to the then revolutionary idea of popular sovereignty and democracy.

During decades, the "tensions" inherent in the field of Public Administration have inspired prolific academic production that is marked by its research interests, which cover many other fields of knowledge, such as Political Science, Business Administration, Sociology, and many others. At the same time, it has drawn closer to these academic communities in an attempt to legitimize a field of knowledge that is constantly seeking scientific authority. The proliferation of academic programs and scientific journals, and numerous attempts at "selfevaluation" aimed at validating the "scientific" nature of this intellectual production are just some examples of this pursuit of legitimacy.

FGV/EBAPE'S Revista de Administração Pública (RAP - Public Administration Journal) was first published in 1967, a few decades after some paradigmatic international journals, such as Public Administration and Public Administration Review first came out. Its goal was to focus the debate, the subjects of interest to the academic community and the practice of Public Administration in general on the Brazilian context. Since then, the RAP has played a historic role in terms of expanding knowledge about Public Administration in Brazil. Its academic

DOI: http://dx.doi.org/10.1590/0034-761212016

Rev. Adm. Pública - Rio de Janeiro 50(1):11-15, jan./fev. 2016 
contribution is widely acknowledged, as evidenced by the A2 level classification awarded it by Qualis, not only in its Administration, Accounting Sciences and Tourism class, but also in that of Political Science and International Relations, and Urban and Regional Planning/ Demographics. The academic prestige of this journal is also reflected in important national and international references - Cabell's, Clase, Diadorim, DOAJ, EBSCO, Gale, LatAm-Studies, Latindex, Lilacs, Proquest, Redalyc, Redib, SciELO, Brasil, Scopus, Sherpa/Romeo, SPELL - in which it is listed, and in its significant readership numbers (over fifteen thousand per month). These are just some of the indicators of its quality and standing in the field.

The present recognition that is given to the RAP is the result of a number of factors. These include: a) institutional support provided by Fundação Getulio Vargas (FGV -Getulio Vargas Foundation) and by Escola Brasileira de Administração Pública e de Empresas (EBAPE -Brazilian School of Public and Business Administration), in the form of human, financial and material resources, considering the journal as an institutional element that contributes to the School's overall mission; b) the team of editors, who have dedicated themselves to the journal over the course of decades, contributing to the process of creating an academic vehicle committed to the quality of the debate on public administration; c) the RAP's reference community - a group of researchers dedicated to subjects related to Public Administration, experts who voluntarily evaluate hundreds of scholarly works and, primarily, readers who consume, convey and provide feedback through a constant flow of ideas, subjects and discussions. These are considered central to the dialogues that form the basis of the process of knowledge building in Public Administration.

It is in this institutional context that I take on, with great honor and responsibility, the position of editor-in-chief of the Revista de Administração Pública. As part of the good editorial practices I have "inherited" from Professor Peter Spink, who has worked for the last five years as editor of this journal, I declare my full commitment to the transparency of the editorial processes. Perhaps uniquely among its national peers, the RAP has opted for a process that is guided by the principles of transparency, adopting the double blind assessment method that applies all the way through, from the desk-review process to final acceptance for publication. As Professor Peter Spink has already highlighted, I hope to transform this editorial experience into an opportunity for learning about the directions and tendencies in the field of Public Administration in Brazil and around the world.

The editorials accompanying the publication of new issues of this journal will serve as a channel of communication with the RAP reference community. In order to improve the evaluation process and encourage a proactive strategy for attracting works more closely identified with the field of Public Administration, I have invited three new members of the academic community to join the Editorial Group. They will join the two existing assistant editors (Fernando G. Tenório and Marco Antonio C. Teixeira) and are as follows: Ricardo Corrêa Gomes (UnB), Leonardo Secchi (Udesc), and Fernando Coelho (USP). I believe this team of assistant editors, renowned for their work in the field of Public Administration will, together with the journal's permanent team of Fabiana Braga Leal, general coordinator and editorial assistant Anderson do Nascimento Ricci, contribute to the continuous improvement of the quality of works published in this journal. 
During these first months working on the edition of the RAP, I have dedicated myself to a more qualitative diagnosis of the works submitted to and conveyed for publication in the journal. I have thus become aware of the challenge posed by the pursuit of a balance between quantitative pressure, a reflection of academic productivism, and the quality of discussions focused on the identity of Public Administration as such. The quantitative pressure is manifested in the significant number of submissions that still lack an appropriate level of research problematization, although they do sometimes "simulate" scientific eloquence in certain structural aspects. Qualitative problems can be perceived in the absence of a dialogue that revives classical and contemporary contributions to the field of Public Administration, in order to identify gaps, overlaps, lack of clarity or ambiguities that justify new research proposals in the field. Consequently, we are still faced with many works that view public administration as a mere locus for field research.

Such pressure results in a diversified roll of publications in the journal, which may become a hindrance to the establishment of thematic, conceptual or methodological dialogues - key to developing relevant and thorough research in Public Administration. In this first RAP edition of 2016, and as part of our pursuit of such coherence, we have endeavored to bring together some articles with a common axis - a stronger emphasis on human and cultural factors in several processes that permeate the public sector dynamic.

The first article, Motivation, retention and job satisfaction in the public service: the case of the Experts in Public Policy and Government Management, by Fabio Alvim Klein and André Ofenhejm Mascarenhas, presents an alternative theoretical view by discussing the extrinsic and intrinsic motivational factors that affect evasion and satisfaction in this modernizing career for the Brazilian public sector. The authors demonstrate that evasion is mainly determined by extrinsic factors related to remuneration while satisfaction is determined not only by extrinsic factors, but chiefly by intrinsic factors linked to the nature of the job. The research results indicate a series of practical implications for career management in the public sector - a neglected subject in the theory and practice of this sector.

Organizational change and work satisfaction: a study of civil servants in Minas Gerais state, by Antônio Luiz Marques, Renata Borges, and Isabella do Couto Reis, aims to understand the implications of organizational changes in the levels of job satisfaction. This is done by analyzing the impacts of one of the key tools of reform adopted by the government of the state of Minas Gerais, namely the individual performance evaluation. In its conclusions, the article highlights the way changes are implemented and their direct influence on job satisfaction levels.

Civil service in Chile, analysis of senior civil servants on the top rung of the hierarchy (2003-2013), by Bastián González-Bustamante, Alejandro Olivares, Pedro Abarca, and Estebam Molina, presents the main factors that influence the selection of high level civil servants in Chile. It focuses on an experience that has been discussed and referred to as benchmarking in the selection of high-level public sector executives in Latin America, Sistema de Alta Dirección Pública.

(Im)Possibilities for Applying the Excellence in Public Management Model (MPEG), by Fernando Filardi, Angilberto Sabino de Freitas, Helio Arthur Irigaray, and Ana Beatriz Ayres, 
analyses the results of the application of the Excellence Model in Public Management at Fundação Oswaldo Cruz (Fiocruz). The article identifies a series of cultural and bureaucratic barriers, as well as other hurdles related to political discontinuity that result in only a partial adoption of the model in the sphere of the complex and bureaucratic organization that is Fiocruz.

Research-action and dialogical mediation as methodological practices favoring the emergence of communication initiatives in Councils of Public Policy Managers, by Carla Beatriz Marques Rocha e Mucci, and Rennan Lanna Martins Mafra, provides an analysis of two methodological practices that support participation within the sphere of the Councils of Public Policy Executives: research-action and dialogic mediation. The authors try to understand how these practices can stimulate the emergence of communicative action in the midst of the participative institutional designs of such councils. Although the study suggests that these practices constitute important mechanisms for qualifying formal participative spaces, the authors also warn that there may be some risks. These include the colonization of participative spaces by the institutions that play leading roles within them.

Finally, the article Social capital and public policies: a comparative study in Vale do Rio dos Sinos, by Everton Rodrigo Santos and Margarete Fagundes Nunes, demonstrates, by means of quantitative and comparative research, that social capital, inherent in the local political culture existing in the area and in the city, is associated with the positive evaluation of municipal public policies. In other words, political institutions that encounter a society that is organized and endowed with social capital i.e. one that is socially productive have a better chance of being successful in their purpose.

This new issue of the journal inaugurates a new forum: Practical Perspectives, in which we shall present works that discuss subjects of practical relevance to the public sector, and which are on the current agenda of debates within Brazilian and international contexts. The purpose of this forum is to attract not only work by researchers, but also by public sector leaders and administrators, in an attempt to build a bridge of dialogue between these two communities. This issue offers the article entitled Voluntary transfers from the Brazilian Federal Government to municipalities: mapping the national scenario by José da Assunção Moutinho, which maps the national scenario of decentralization through voluntary transfers, in order to identify possible concentrations. The indications are that there is a heterogeneous distribution of resources among Brazilian municipalities, with a strong concentration in the Southern region, and a much higher rate of approved proposals deriving from parliamentary amendments than resulting from the ministries' own pre-defined programs. This suggests scope for a future research agenda that should explore the reasons for such a distribution.

I would like to conclude this editorial by announcing an important initiative promoted by the RAP, which lies within the scope of a more proactive strategy for promoting research based on the stringency and relevance of Public Administration. I refer here to the workshop entitled International Research in Public Administration: building bridges for rigorous and relevant research, to be held on February 26, 2016, in cooperation with the JPART's editorial team (The Journal of Public Administration Research and Theory).

The JPART is the most renowned academic journal on Public Administration, this according to the high factors published in 2015 by Journal Citation Reports. The workshop 
aims to build a space for dialogue for the Brazilian academic community and the journal's associated maintainer, the Public Management Research Association, in an attempt to promote academic research cooperation over the coming years. Interested researchers may contact us via email, rap@fgv.br, for further information.

Enjoy the read!

Alketa Peci

Editor-in-Chief

Alketa Peci is Ph.D. in Administration and Professor of Brazilian School of Public and Business Administration of Getulio Vargas Foundation. Editor-in-chief of Revista de Administração Pública - RAP. E-mail: alketa@fgv.br 